\title{
Musculoskeletal symptoms and physical risk factors among automobile mechanics in Dhaka, Bangladesh
}

\author{
Shamima Akter ${ }^{1}$, Mahammad Mominur Rahman ${ }^{2}$, Shipra Mandal ${ }^{3}$, Nazmun Nahar ${ }^{4}$ \\ ${ }^{1,3}$ Lecturer, ${ }^{2}$ Occupational Therapist; ${ }^{4}$ Assistant Professor; Department of Occupational Therapy, Bangladesh Health Professions \\ Institute, Centre for the Rehabilitation of the Paralysed, Chapain, Savar, Dhaka, Bangladesh.
}

\begin{abstract}
The occupational health and safety service is still in the developing stage. In Bangladesh, this service is merely focused on welfare for the garments workers. Statistics on musculoskeletal symptoms prevalence and risk factors analysis for any occupational group can assist to develop ergonomic based prevention and intervention programs. However, there is no information available about the musculoskeletal symptoms prevalence amongst automobile mechanics in Bangladesh. The aim of study is to estimate the prevalence of musculoskeletal symptoms and reveal association with physical risk factors among automobile mechanics. This cross-sectional study was performed with 100 automobile workers conveniently selected from different automobile workshop of Dhaka Division (Savar and Gabtoli) of Bangladesh. The short version of Dutch Musculoskeletal Questionnaire was used to determine the prevalence and associated physical risk factors. Furthermore, the Rapid Entire Body Assessment was used to identify the physical risk level of musculoskeletal symptoms. The prevalence of musculoskeletal symptoms during the last 12 months preceding data collection was reported at $77 \%$. The most affected body parts were lower back $(67 \%)$ then the hip $(53 \%)$. Socio-demographic and physical risk factors were significantly $(\mathrm{p}<0.05)$ associated with reported musculoskeletal symptoms. It is highly concerning issue for employing occupational health and safety program for those workers.
\end{abstract}

Keywords: Automobile mechanics, Musculoskeletal symptoms, Occupational Health and Safety, Ergonomics,

\section{Introduction}

Worldwide occupational illness and injury continue to be the foremost cause of increase cost approximately 2.8 trillion USD (4\%) of annual GDP due to sickness absence, lost work day, worker's compensation and daily production interruption. ${ }^{1}$ These leading to serious impact on physical, psychosocial and economical aspects of the working population. $^{2-8}$ It has been also recognized as a major concern to both developed and developing countries. $^{2,6,8}$ According to the 2014 estimation, Bangladesh, as a developing country, was ranked in the $7^{\text {th }}$ position in the world for having intensive labor force, ${ }^{9}$ The total size of the working population is about 80.27 million and $13 \%$ of this total labor force is working in the industrial sectors. ${ }^{10}$

Every year in Bangladesh, approximately 24.50 thousand died from work-related disease in all sectors, additional 8 million workers faced work-related injury, estimated on 2014 by gathering available data. ${ }^{11}$ However, the occupational health and safety service is still in the development stage and does not intensively cover all recognized occupations or working sites in Bangladesh. ${ }^{2,8,11}$

Particularly, occupational health and safety service which is confined in readymade garment sectors as there have been some recent attention due to tragedies of Tazreen and Rana Plaza garments factories. ${ }^{12}$ Here, poor health and safety conditions are still a challenge to all other working sites, predominantly, heavy manual material handling tasks are commonly reported in literatures. ${ }^{2,4,8}$

\section{Practice Points}

- Musculoskeletal symptoms are very common condition worldwide. It affects people's activity performance in their everyday life.

- The study estimated that $77 \%$ automobile mechanics had been troubled with musculoskeletal symptoms in at least one region in the body.

- The most affected body parts were lower back $(67 \%)$ then the hip (53\%). Socio-demographic and physical risk factors were significantly associated with reported musculoskeletal symptoms.

- Other key risk factors for musculoskeletal symptoms were long working hours, employment duration, and posture.

- Standardized ergonomics approach would allow to prevent or promote the management of workrelated musculoskeletal symptoms.

The workers of the car repairing workshop usually involve in heavy manual material handling task, thus many workers may have injury while working there. ${ }^{13}$ A study reveals that $87.4 \%$ of car repairing workers in Malaysia had reported musculoskeletal disorder. ${ }^{14}$ Another study found that $96 \%$ of automobile mechanics in Norway felt pain, ache or discomfort in one or more parts of the body during the past 12 months due to the complex working nature. ${ }^{6}$ That

Correspondence: Shamima Akter, Lecturer, Department of Occupational Therapy, Bangladesh Health Professions Institute, Centre for the Rehabilitation of the Paralysed, Chapain, Savar, Dhaka, Bangladesh. Email: shamima_ot@ymail.com.

South East Asia Journal of Public Health 2016;6(1):8-13. C 2016 Akter et al., publisher and licensee Public Health Foundation Bangladesh. This is an Open Access article which permits unrestricted non-commercial use, provided the original work is properly cited. 
study also explored that automobile mechanics involved in great physical risk tasks due to working in standing, sitting and lying position for long periods of time in awkward postures. For example: twisted and flexed trunk under the car bonnet and underneath the automobile $^{6}$ and also occupied in repetitive movements and have to control heavy vibrating tools with force. ${ }^{14}$ These factors may contribute to increased pain and numbness sensations in different body areas.

In Bangladesh, there is scarce evidence regarding the situation of the automobile mechanics. The purpose of this study was to examine the prevalence of musculoskeletal symptoms and their association with physical risk factors amongst the automobile mechanics in Dhaka, Bangladesh.

\section{Materials and methods}

The study was conducted in conveniently selected places at Gabtoli and Savar. Gabtoli is one of the largest and vital bus terminals in Bangladesh where long route buses both start and stop at the same place, or may be in different locations for arriving and leaving a route. Savar bus stand is another important route for the communication with Dhaka to the Northern and Southern part of Bangladesh. Several garages and automobile workshops are situated in Gabtoli and Savar bus stand.

The automobile workers are mainly involved with more or less same patterns of works. They usually perform maintenance of engine tune-ups, oil changes, tire rotation and changes, wheel balancing, repairing mechanical and electrical systems dysfunctions; raises vehicle using hydraulic jack; replacing parts and components; repairing car's damaged body; maintaining vehicle appearance by cleaning, washing, and painting. ${ }^{14-20}$

A cross-sectional survey method was designed to reveal the prevalence during the time period of 12 months prior to data collection. Workers of the automobile workshop and automobile garages, whose involved in repairing cars and taxicabs are the population of the study. Male automobile workers age range from 14-45 years who had employed in the automobile workshops or garages for at least 12 months prior to data collection were included in the study as participants. According to the Bangladesh Labor Law 2010, the minimum age of working is 14 years. $^{21}$ The workers who had joint disease, gout, diabetes and trauma during one year before the data collection was excluded because the symptoms of those conditions were similar to symptoms of work-related musculoskeletal symptoms. ${ }^{15}$ Purposive sampling procedure was used to select 100 participants based on inclusion and exclusion criteria.

The study was approved by the Internal Review Committee (IRB) of the Bangladesh Health Professions Institute. The legal authorities of automobile workshops and garages also provided written permission to conduct the study at their sites without any disruption to their daily work flow. The investigator fixed a date and time with the selected participants, according to their preferable available time. The ethical issues were maintained throughout the study by the means of consent form based on anonymity, beneficence, autonomy and justice.
The Dutch Musculoskeletal Questionnaire (DMQ) was preferred as a data collection instrument by investigator, as because it is widely used by ergonomist and occupational health professionals as a standardized tool to find out the prevalence and associated physical and psychological risk factors of musculoskeletal symptoms from different working population by easy, quick and a systematic way. ${ }^{22}$

The data were collected from the participants using a short translated 'Bengali final version' of the Dutch Musculoskeletal Questionnaire. For translating DMQ into Bengali, the investigator followed the translation guidelines of World Health Organization. ${ }^{23}$ In the first step, two translators were selected for forward translation $\mathrm{A}$ and $\mathrm{B}$. Both translators converted the original DMQ in Bengali independently with a focus to produce familiar and easily understandable language but not an exact translation of wording. After receiving independent forward A and B translation, the investigator and a linguistic expert discussed two forward versions of these questionnaires during a meeting. Then they approved a combined version from $\mathrm{A}$ and $\mathrm{B}$ in order to produce a conceptually equivalent translation named Bangla version DMQ 1.0. After finalizing the Bangla version DMQ 1.0, the investigator sent the questionnaire to bilingual expert who did not have any access to the original English version of the questionnaire. After that comparison of this backward translation with Bangla Version DMQ 1.0 was done to find out any inconsistencies, errors, mistranslations, imprecision. After resolving misunderstanding in the Bangla version 1.0 and in backward translation, finally DMQ version 2.0 was accomplished for the field test with 5 participants who speak in Bangla language in order to conduct a comprehension test through face to face interview.

During this period, the investigator investigated whether the subject had any difficulty in understanding and also examined the participants' interpretation or expression of all questions. Based on participants' interpretation what they choose better alternatives to their usual language the third version of the questionnaire was developed. The Bangla version DMQ 3.0 was considered as Bengali final version. The cronbach's alpha coefficient in the total sample was 0.95 , and it was suggested that item had significantly high internal consistency.

The Rapid Entire Body Assessment (REBA) was used to identify the physical risk level of developing musculoskeletal symptoms among automobile workers. REBA was developed by Hignett, to provide information on musculoskeletal risk action level by a quick and easy observational postural analysis tool for whole static and dynamic activities. ${ }^{24-26}$ The investigator observed the automobile mechanics' trunk, neck, legs, upper arms, lower arms and wrists movement or position during working in their actual work settings.

Data input and analysis were performed by the Statistical Package for Social Science (SPSS), version 17 (SPSS Inc., Chicago, IL, USA) to increase the trustworthiness of the analysis and lessen the influence of the missing value. The process of data analysis was followed the study aim and objectives. Descriptive analysis was used to find out the frequency and 
percentage of different socio-demographic data and prevalence of musculoskeletal symptoms. A chi-square test was conducted at with $p<0.05$, to find out the association between the prevalence of musculoskeletal symptoms and socio-demographic and physical risk factors.

\section{Results}

The distribution of socio-demographic characteristics of respondents are shown in Table 1. The age range of the study participants was $14-45$ years. More than half of the participants $(52 \%)$ received formal education up to the secondary level and $8 \%$ participants were illiterate. Three-quarters of the respondents hold the job title as main worker and $84 \%$ of participants worked daily more than 8 hours in automobile workshop and garage. The greatest part of participants' monthly income was more than 6000 BDT (\$7.5).

In this study, it was found that $77 \%$ automobile mechanics had been troubled with musculoskeletal symptoms in at least one region in the body over the last 12 months (Figure 1).

Table 2 illustrated that there was significant association between musculoskeletal symptoms prevalence in the last 12 months preceding data collection and job title ( $p$ $0.013)$, monthly income ( $p-0.000)$, employment duration $(p-0.002)$, daily working hours $(p-0.005)$. However, no significant association between at least one region pain in last 12 months \& age $(p-0.079)$, educational qualification $(p-0.166)$.

On the other hand, Table 3 demonstrates that there is highly significant association between reported musculoskeletal symptoms in the last 12 months and force exertion $(p-0.000)$, lifting $(p-0.000)$, vibration $(p$ -
Table 1: Socio-demographic characteristics of the respondents

\begin{tabular}{|l|c|}
\hline Background Factors & $\begin{array}{c}\text { Respondents (\%) } \\
\text { (N=100) }\end{array}$ \\
\hline Age & $78(78 \%)$ \\
15-30 years & $22(22 \%)$ \\
\hline 31-45 years & $8(8 \%)$ \\
\hline Educational qualification & $40(40 \%)$ \\
Illiterate & $52(52 \%)$ \\
Primary & \\
Secondary & $76(76 \%)$ \\
\hline Job title & $24(24 \%)$ \\
Main worker & $8(8 \%)$ \\
Helper & $32(32 \%)$ \\
\hline Monthly income & $60(60 \%)$ \\
Less than 3000 BDT & $16(16 \%)$ \\
3001-6000 BDT & $23(23 \%)$ \\
More than 6000 BDT & $61(61 \%)$ \\
\hline Employment duration & $16(16 \%)$ \\
1-3 years & $84(84 \%)$ \\
4-6 years & \\
More than 6 years & \\
Daily working hours & Up to 8 hours \\
More than 8 hours &
\end{tabular}

0.001), repetitive movement ( $p-0.001)$, awkward posture $(p-0.012)$.

Furthermore, Table 4 reveals that $43 \%$ automobile mechanics are in medium risk level to develop musculoskeletal symptoms due to extreme body posture and position. Significant association was found between at least one region pain in last 12 months \& REBA score $(p-0.000)$ for developing musculoskeletal symptoms.

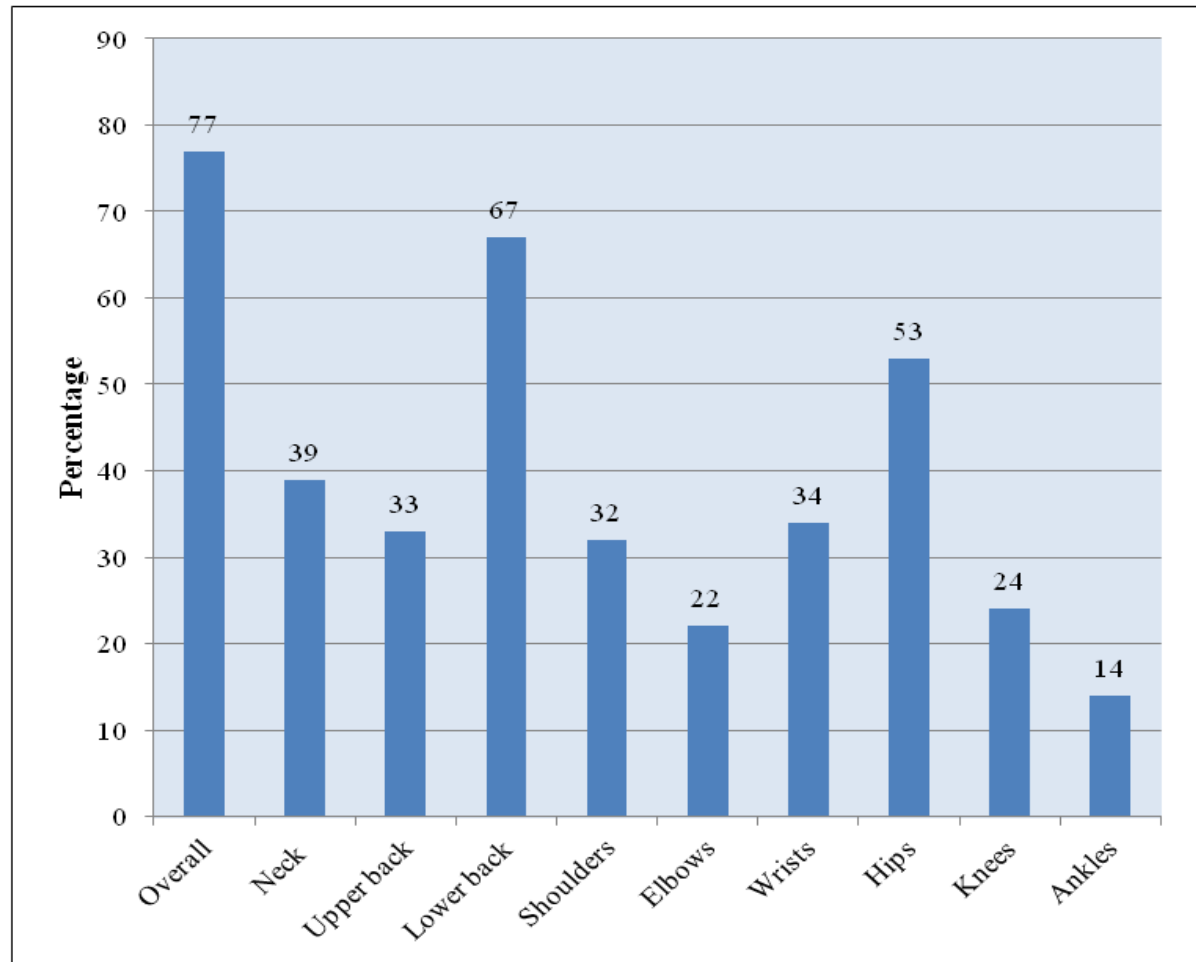

Figure 1: The prevalence musculoskeletal symptoms in nine body regions at last 12 months prior to data collection 
Table 2: Association between socio-demographic factors and reported musculoskeletal symptoms (at least one region pain in the last 12 months)

\begin{tabular}{|c|c|c|c|}
\hline \multirow{2}{*}{$\begin{array}{l}\text { Socio-demographic } \\
\text { factors }(n=100)\end{array}$} & \multicolumn{2}{|c|}{ Respondents (\%) } & \multirow{2}{*}{$\begin{array}{l}p \text { - } \\
\text { value* }\end{array}$} \\
\hline & Yes & No & \\
\hline \multicolumn{3}{|l|}{ Age } & \multirow{3}{*}{0.079} \\
\hline $15-30$ years & $57(57 \%)$ & $21(21 \%)$ & \\
\hline $31-45$ years & $20(20 \%)$ & $2(02 \%)$ & \\
\hline \multicolumn{3}{|c|}{ Educational qualification } & \multirow{4}{*}{0.166} \\
\hline Illiterate & $8(08 \%)$ & - & \\
\hline Primary & $28(28 \%)$ & $12(12 \%)$ & \\
\hline Secondary & $41(41 \%)$ & $11(11 \%)$ & \\
\hline \multicolumn{3}{|l|}{ Job title } & \multirow{3}{*}{0.013} \\
\hline Main worker & $63(63 \%)$ & $13(13 \%)$ & \\
\hline Helper & $14(14 \%)$ & $10(10 \%)$ & \\
\hline \multicolumn{3}{|l|}{ Monthly income } & \multirow{4}{*}{0.000} \\
\hline$>3000 \mathrm{BDT}$ & $1(01 \%)$ & $7(07 \%)$ & \\
\hline 3001-6000 BDT & $20(20 \%)$ & $12(12 \%)$ & \\
\hline$>6000 \mathrm{BDT}$ & $56(56 \%)$ & $4(04 \%)$ & \\
\hline \multicolumn{3}{|l|}{ Employment duration } & \multirow{4}{*}{0.002} \\
\hline $1-3$ years & $8(56 \%)$ & $8(08 \%)$ & \\
\hline 4-6 years & $15(15 \%)$ & $8(08 \%)$ & \\
\hline$>6$ years & $54(54 \%)$ & $7(07 \%)$ & \\
\hline \multicolumn{3}{|l|}{ Daily working hours } & \multirow{3}{*}{0.005} \\
\hline Up to 8 hours & $8(54 \%)$ & $8(08 \%)$ & \\
\hline$>8$ hours & $69(69 \%)$ & $15(15 \%)$ & \\
\hline
\end{tabular}

*Chi-square test, $\mathrm{p}<0.001$

Table 3: Association between reported physical risk factors and musculoskeletal symptoms prevalence

\begin{tabular}{|l|c|c|c|}
\hline \multirow{2}{*}{$\begin{array}{l}\text { Reported physi- } \\
\text { cal risk factors }\end{array}$} & \multicolumn{2}{|c|}{ Respondent (\%) } & \multirow{2}{*}{$\begin{array}{c}\text { Y- } \\
\text { value* }\end{array}$} \\
\cline { 1 - 2 } Awkward posture & No & \multirow{2}{*}{0.012} \\
\hline Yes & $76(76 \%)$ & $20(20 \%)$ & \\
\hline No & $1(01 \%)$ & $3(03 \%)$ & \\
\hline Repetitive movement & \multirow{2}{*}{0.001} \\
\hline Yes & $71(71 \%)$ & $15(15 \%)$ & \\
\hline No & $6(06 \%)$ & $8(08 \%)$ & \\
\hline Force exertion & $69(69 \%)$ & $13(13 \%)$ & \multirow{2}{*}{0.000} \\
\hline Yes & $8(08 \%)$ & $10(10 \%)$ & \\
\hline No & $67(67 \%)$ & $11(11 \%)$ & \multirow{2}{*}{0.000} \\
\hline Lifting & $10(10 \%)$ & $12(12 \%)$ & \\
\hline Yes & $57(57 \%)$ & $08(08 \%)$ & \multirow{2}{*}{0.001} \\
\hline No & $20(20 \%)$ & $15(15 \%)$ & \\
\hline Vibration & & \\
\hline Yes & & \\
\hline No &
\end{tabular}

*Chi-square test, $\mathrm{p}<0.001$

Table 4: Association between the risk level of car mechanics according to REBA score and reported musculoskeletal symptoms at last 12 month prior to data collection

\begin{tabular}{|l|c|c|c|}
\hline \multirow{2}{*}{ REBA score } & \multicolumn{2}{|c|}{ Respondent (\%) } & \multirow{2}{*}{$\begin{array}{c}\text { - } \\
\text { value* }\end{array}$} \\
\cline { 2 - 3 } 1 (Negligible) & Yes (\%) & No (\%) & \multirow{2}{*}{0.000} \\
\hline 2-3 (Low) & $34(34 \%)$ & $20(20 \%)$ & \\
\hline 4-7 (Medium) & $43(43 \%)$ & $03(03 \%)$ & \multirow{2}{*}{0.000} \\
\hline 8-10 (High) & - & - & \\
\hline $11-15$ (Very high) & - & - & \\
\hline
\end{tabular}

*Chi- square test, $\mathrm{p}<0.001$
In the present study, seventy seven percent of the participants reported pain or numbness in at least one body part among the nine defined body regions. In a study conducted in Malaysia found that $87.4 \%$ of auto repair mechanics suffered from MSD.

The prevalence of musculoskeletal symptoms is not much deviated from the UK-based study ${ }^{4}(73 \%)$, however, higher prevalence reported in a study conducted in Norway. In the study conductrd by Torp et al. ${ }^{6}$ found high prevalence in the last 12 months preceding data collection rather than automobile mechanics of Bangladesh. Recall bias may be a possible cause of reporting low prevalence by Bangladeshi workers.

We found lower back pain as the most prevalent body area $(67 \%)$ in our study. Other prevalent body areas of this study are hip, neck and upper back. A study in Bangladesh estimated that $78 \%$ of professional car drivers suffer from LBP. ${ }^{25}$ Various studies showed that lower back pain was the most prevalent musculoskeletal symptoms in Norway $(76 \%)^{6}$ and United Kingdom $(65 \%)^{4}$ among the automobile mechanics.

The present study also demonstrated that almost all of automobile mechanics are in risk according to the REBA assessment in terms of awkward posture with twisted and flexed position of the trunk and neck. The automobile mechanics usually work in a standing position under the bonnet by bending the neck forwardly more than $40^{\circ}$ for 5-6 hours of their total working time whereas according to REBA, working with the neck bent position more than $40^{\circ}$ for one hour indicates greater risk. Likewise, these workers do their work in same position with bent trunk more than $30^{\circ}$ for the same 5-6 hours. This awkward posture causes constant pressure on spinal and neck muscles and also causes stress and strain on ligament lead to increase inter-disc pressure and liable to pain and possibility of injury in those area. $^{15}$ Therefore, musculoskeletal related complaints in back and neck is highly reported by them. Previous study reported that the automobile mechanics required great physical effort, heavy lifting and carrying, awkward movement of lower back, force exertion, vibration, and repeated movement. ${ }^{13}$ In several studies, the researcher found that the physical risk factors such as awkward working postures, static load and task invariability that might contribute to the development of musculoskeletal symptoms in different regions of body. $2,4,6,8,13$

The second most prevalent body region of the present study is hip although not significantly related to other study; the possible causes are the pattern of the work is different from the workers of the developed countries. The participants of this study had to work in supine posture with forwardly flexed neck and spine for working underneath the car for 2-3 hours. It may cause high physical loading in the lower back and hip region. Similarly, strain and stress on lower back and hip areas are common for the workers as they also had to sit in squat position or on floor for long time during heavy mechanical works or during using heavy vibration tools. The injuries can also occur from 
handling heavy objects, heavy lifting, and prolonged or sustained work in this type of awkward postures. ${ }^{2,8,13}$ The fact is that the investigators also found the similar consequences as the workstation was not adjusted with their height, workers were working in twisted trunks and necks as well as heavy loads were carried by them more frequently without taking any significant rest.

Moreover, the study findings also showed a significant association at least one regional pain in last 12 months for developing musculoskeletal symptoms and physical risk factors such as awkward posture, repetitive movement, force exertion, lifting and vibration as shown in other study. ${ }^{13}$

Findings of this study show a significant association between some socio-demographic factors and musculoskeletal symptoms at least one regional pain in the last 12 months. In another study, the investigators found that there had an association between musculoskeletal symptoms and age, employment duration; increasing age and employment duration are known to be associated with an increasing prevalence of musculoskeletal symptoms. ${ }^{6}$

There are some factors limiting the extrapolation of findings from this investigation. The overall sample size was relatively small and the place were selected by the convenient method and samples were chosen only two areas of Bangladesh in Dhaka. The result of the present study should be generalized with caution. There is no available data in similar context to compare the result more intensively.

\section{Conclusion}

Inadequate evidence regarding musculoskeletal symptoms prevalence and its impact on quality of life of automobile mechanics are available in Bangladesh. The study result reveals that Bangladeshi automobile workers are in risk due to the demand of poor ergonomic working environment by analyzing posture and pattern of movements. Thus, this study provides a snapshot of present situation only; a future large-scale investigation of the incidence of musculoskeletal symptoms among automobile mechanics is necessary. This study results provide baseline information to adapt ergonomic approach for automobile mechanics. A standardized ergonomics approach would allow preventing or promoting the management of workrelated musculoskeletal symptoms amongst automobile mechanics.

\section{Competing interest}

The authors declare that they have no competing interests.

\section{References}

1. Takala J, Hämäläinen $\mathrm{P}$, Saarela KL, Yun LY, Manickam K, Jin TW, Heng P, Tjong C, Kheng LG, Lim S, Lin GS. Global estimates of the burden of injury and illness at work in 2012. $J$ Occp and Environ Hyg 2014;11:326-37.

2. Akter S, Maruf M, Uddin Z, Chowdhury SK. Prevalence of musculoskeletal symptoms and associated factors: A cross-sectional study of metal workers in Bangladesh. Work 2015; 50:363-70.

3. Deros BM, Daruis DD, Ismail AR, Sawal NA, Ghani JA. Work-related musculoskeletal disorders among workers' performing manual material handling work in an automotive manufacturing company. Amer J Appli Sci 2010;7:1087.

4. Hussain T. Musculoskeletal symptoms among truck assembly workers. Occup Med 2004;54:506-12.

5. Woolf AD, Pfleger B. Burden of major musculoskeletal conditions. Bull the World Health Org 2003;81: 646-56.

6. Torp S, Riise T, Moen BE. Work-related musculoskeletal symptoms among car mechanics: a descriptive study. Occup Med 1996;46:407-13.

7. Nuwayhid IA. Occupational health research in developing countries: a partner for social justice. Amer J Public Health 2004;94:1916-21.

8. Ahasan R. Work-related research, education and training in developing countries. Work Study 2003;52:290-6.

9. Central Intelligence Agency (CIA). The World Fact Book. South Asia: Bangladesh. Economy. https://www.cia.gov/library/publications/theworld-factbook/geos/bg.html (accessed June 2016)

10. Central Intelligence Agency (CIA). The World Fact Book. South Asia: Bangladesh. Labor Force. https://www.cia.gov/library/publications/ the-world-factbook/geos/bg.html (accessed June 2016)

11. International Labor Force. Safety and health at work in Bangladesh. http://www.ilo.org/dhaka/ Areasofwork/safety-and-health-at-work/lang--en/ index.htm (accessed June 2016)

12. Tazreen A, Sabet DM. Worker Safety in Bangladesh: Looking Beyond Garments. Dhaka: University of Liberal Arts, 2015.

13. Rahman A, Nasrull M, Abdul Aziz F, Mohd Yusuff R. Investigation of ergonomic risk factors in a car tyre service centre. National Symposium on Advancements in Ergonomics and Safety, Perlis, Malaysia, 1-2 Dec 2009.

14. Nasaruddin AF, Tamrin SB, Karuppiah K. The Prevalence of Musculoskeletal Disorder and the Association with Risk Factors among Auto Repair Mechanics in Klang Valley, Malaysia. Iranian J Public Health 2014;43(3):34-41.

15. Punnett L, Wegman DH. Work-related musculoskeletal disorders: the epidemiologic evidence and the debate. J Electromyogr Kines 2004;14:13 -23 . 
16. Chowdhury SS, Boricha J, Yardi S. Identification of awkward postures that cause discomfort to Liquid Petroleum Gas workers in Mumbai, India. Indian J Occup Environ Med 2012;16:3.

17. Sethi D, Sharma A. A Study to Explore the Experiences of Occupational Hazards among the Motor Mechanics Working in Automobile Workshops at Kurali (Punjab). Int J Nur Care 2016; 4:88-91.

18. Nahar BN, Ashan GU, Khan NA. Prevalence of low back pain and associated risk factors among professional car drivers in Dhaka city. South East Asia J Public Health. 2013;2:60-3.

19. Rahman FM. Work related musculo-skeletal disorders among the truck drivers. [dissertation]. Department of Physiotherapy, Bangladesh Health Professions Institute, Dhaka, Bangladesh, 2013.

20. Al-Mabud, M. Prevalence of neck pain among the highway bus drivers. Department of Physiotherapy, Bangladesh Health Professions Institute, Dhaka, Bangladesh, 2013.
21. Bangladesh Bureau of Statistics. Statistical pocket book of Bangladesh 2008. Dhaka: Bangladesh Bureau of Statistics, 2009.

22. World Health Organization. Process of translation and adaptation of instruments. http:// www.who.int/substance abuse/research tools/ translation/en/ (accessed June 2016)

23. Hildebrandt VH, Bongers PM, Van Dijk FJ, Kemper HC, Dul J. Dutch Musculoskeletal Questionnaire: description and basic qualities. Ergon 2001;44:1038-55.

24. Hignett S, McAtamney L. Rapid entire body assessment (REBA). App Ergo 2000;31:201-5.

25. Ansari NA, Sheikh MJ. Evaluation of Work Posture by RULA and REBA: A Case Study. IOSR J Mec and Civil Eng 2014;11:18-23.

26. Middlesworth M. Ergonomic plus. A step-bystep guide to REBA Assessment Tool. http://ergo -plus.com/reba-assessment-tool-guide/ (accessed June 2016) 